\title{
Enhancement of Efficiency of Activated Carbon Impregnated Chitosan for Carbon Dioxide Adsorption
}

\author{
Chaiwat Patkool $^{1}$, Petchporn Chawakitchareon ${ }^{1 \dagger}$, Rewadee Anuwattana ${ }^{2}$ \\ ${ }^{1}$ Department of Environmental Engineering, Faculty of Engineering, Chulalongkorn University, Bangkok 10330, Thailand \\ ${ }^{2}$ Environment and Resources Technology Department, Thailand Institute of Scientific and Technological Research, Pathumthani 12120, Thailand
}

\begin{abstract}
The effect of carbon dioxide $\left(\mathrm{CO}_{2}\right)$ on global warming is serious problem. The adsorption with solid sorbents is one of the most appropriate options. In this study, the most interesting adsorbent is granular activated carbon (GAC). It is suitable material for $\mathrm{CO}_{2}$ adsorption because of its simple availability, many specific surface area, and low-cost material. Afterwards, GAC was impregnated with chitosan solution as impregnated granular activated carbon (CGAC) in order to improve the adsorption capacity of GAC. This research aims to compare the physical and chemical characteristics of GAC and CGAC. The experiment was carried out to evaluate the efficiency of $\mathrm{CO}_{2}$ adsorption between GAC and CGAC. The results indicated that the iodine number of GAC and CGAC was 137.17 and $120.30 \mathrm{mg} / \mathrm{g}$, respectively. The Brunauer-Emmett-Teller results (BET) of both GAC and CGAC show that specific surface area was 301.9 and $531.3 \mathrm{~m}^{2} / \mathrm{g}$, respectively; total pore volume was 0.16 and 0.29 $\mathrm{cm}^{3} / \mathrm{g}$, respectively; and mean diameter of pore was 2.18 and $2.15 \mathrm{~nm}$, respectively. Finally, the $\mathrm{CO}_{2}$ adsorption results of both GAC and CGAC in single column how the maximum adsorption capacity was 0.17 and $0.25 \mathrm{~mol} / \mathrm{kg}$, respectively; how degeneration time was 49.6 and 80.0 min, respectively; and how the highest efficiency of $\mathrm{CO}_{2}$ adsorption was $91.92 \%$ and $91.19 \%$, respectively.
\end{abstract}

Keywords: Carbon dioxide adsorption, Chitosan, Global warming, Granular activated carbon

\section{Introduction}

The greenhouse effect is attributed to increase in the emission of the greenhouse gases, such as carbon dioxide $\left(\mathrm{CO}_{2}\right)$, methane $\left(\mathrm{CH}_{4}\right)$, nitrous oxide $\left(\mathrm{N}_{2} \mathrm{~N}_{2} \mathrm{O}\right)$, chlorofluorocarbons (CFC), and sulfur hexafluoride $\left(\mathrm{SF}_{6}\right)$. Among them, $\mathrm{CO}_{2}$ is the main greenhouse gas that causes global warming [1] because $\mathrm{CO}_{2}$ mostly increases among other greenhouse gases which was increased by $45 \%$ between 1990 and 2010 [2].

The most important sources of $\mathrm{CO}_{2}$ emission is the human activities. Including, burning fossil fuels (coal, oil, natural gas) and various industrial processes, such as distillation of petroleum, manufacturing cement, and metal smelting. There were several post-combustion gas separation and capture technologies being investigated, such as amine scrubber, thermal separation, membrane separation, biofixation, and pressure swing adsorption (PSA) [3].

At present, the preferred technology which carries out the separation of $\mathrm{CO}_{2}$ in post-combustion applications is amine scrubbing. However, this technology presents several disadvantages because amine scrubbing requires high energy to regenerate solvent and special management from especial officer. Thus, other technologies for development seek to reduce the cost in the captured steps as adsorption with activated carbon which has high adsorption capacity at ambient pressure, easy regeneration, low-cost, and insensitiveness to moisture.

The adsorption capacity of activated carbon is mainly governed by its texture, but it is also strongly influenced by the surface chemistry. Commercial activated carbon is interesting due to low-cost and simple availability. The commercial activated carbon will be modified with impregnation in chitosan to increase the efficiency for $\mathrm{CO}_{2}$ adsorption because chitosan solution will be ligand for adhesion of adsorbate [4]. Thus, activated carbon will have a more adsorption capacity. Next, activated carbon impregnated chitosan was carried out to adsorb $\mathrm{CO}_{2}$. Finally, in order to determinate $\mathrm{CO}_{2}$ adsorption capacity was carried out in single column of the PSA.

\section{Materials and Methods}

\subsection{Preparation of Activated Carbon}

Commercial granular activated carbon (CGAC) was purchased by

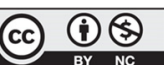

This is an Open Access article distributed under the terms of the Creative Commons Attribution Non-Commercial License (http://creativecommons. org/ licenses/by-nc/3.0/) which permits unrestricted non-commercial use, distribution, and reproduction in any medium, provided the original work is properly cited.
Received May 31, 2014 Accepted September 10, 2014

$\dagger$ Corresponding author

E-mail: petchporn.c@gmail.com

Tel: +66-2-218-6667 Fax: +66-2-218-6666

Copyright (C) 2014 Korean Society of Environmental Engineers 
METRA Co. Ltd. which was selected and separated with the particle size approximately 1.8-2.0 mm. Then, both samples were dried in the hot air oven at $105^{\circ} \mathrm{C}$ for $24 \mathrm{hr}$. Keep a dry sample in the desiccator before chitosan impregnation method.

The commercial chitosan (CS) was purchased from SIGMA Co. Ltd. which was used to prepare stock chitosan solution at concentration by $0.1 \%$ in $100 \mathrm{~mL}$ acetic acid. Next, The GAC would be immersed in chitosan solution for $24 \mathrm{hr}$ at room temperature. Afterwards, filtering and washing with distilled water to remove the excess chemicals on the surface of adsorbent. After previous steps, this sample was called that CGAC which would be dried in the hot air oven at $105^{\circ} \mathrm{C}$ for $24 \mathrm{hr}$.

\subsection{Characterization of Samples}

The chemical and physical characteristics of GAC and CGAC were analyzed as shown.

- The measurement of iodine number corresponding to procedure established by the standard method ASTM D4607-94 (2011) [5]. The measurement of specific surface area, pore volume, and pore size were determined by nitrogen adsorption-desorption isotherms at $77 \mathrm{~K}$ with discontinuous volumetric apparatus (Quantachrome AUTOSORB 1) [6].

- Analysis of the surface functional group by using Fourier transforms infrared spectroscopy (FTIR) of the GAC before and after chitosan treating which is evaluated using Nicolet Magna 560 [7].

- Analysis of morphology of samples. In order to know the surface structure of GAC and CGAC. Morphological analysis was carried out by scanning electron microscope (SEM) by using JSM-6400 scanning microscope model JEOL.

\subsection{Adsorption Experiments}

Both samples were analyzed $\mathrm{CO}_{2}$ adsorption in single column of PSA (Fig. 1).

The chemical compositions of mixed gas were $40 \% \mathrm{CO}_{2}$ and $60 \% \mathrm{~N}_{2}$. Next, feeding mixed gas at controlled pressure of 3 bars with the ratio of flow rate (inlet/outlet) of 1 .

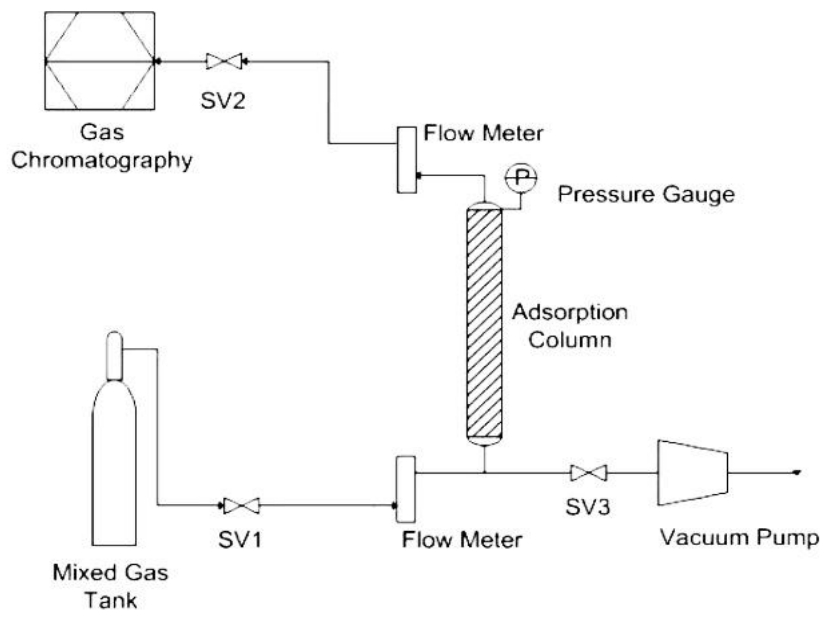

Fig. 1. Diagram of single column system.
Finally, the outlet gas will be collected to analyze the composition of gas by gas chromatograph (Shimadzu model GC2014).

\section{Results and Discussion}

\section{1. lodine Number Result}

The iodine number of GAC and CGAC were shown in table 1 which was 137.17 and $120.30 \mathrm{mg} / \mathrm{g}$, respectively. Reduction of iodine number in CGAC after impregnation which was caused blocking of iodine in microporous CGAC, but CGAC that will get smoother surface [4].

\subsection{BET Surface Area Analysis Result}

Analytical results by adsorption and desorption technique with $\mathrm{N}_{2}$ gas in both GAC and CGAC in Table 1 show that specific surface area were 301.9 and $531.3 \mathrm{~m}^{2} / \mathrm{g}$, respectively; total pore volume were 0.16 and $0.29 \mathrm{~cm} 3 / \mathrm{g}$, respectively; and mean diameter of pore were 2.18 and $2.15 \mathrm{~nm}$, respectively. Conclusion, the results show that impregnation with chitosan that increases the specific surface area and pore volume because film layer of chitosan which coat surface area on GAC [8].

\subsection{Fourier Transform Infrared Spectroscopy Result}

Fourier transform infrared spectroscopy (FTIR) of chitosan and both samples that the peaks with about the $\mathrm{C}=\mathrm{O}$ stretching, amide and amine group in chitosan have appeared at wave numbers 1,704 and 1,650 $\mathrm{cm}^{-1}$. Thus conferred peaks of wave number were distinguished in CGAC (Fig. 2), but those wave numbers were not clearly appear in GAC.

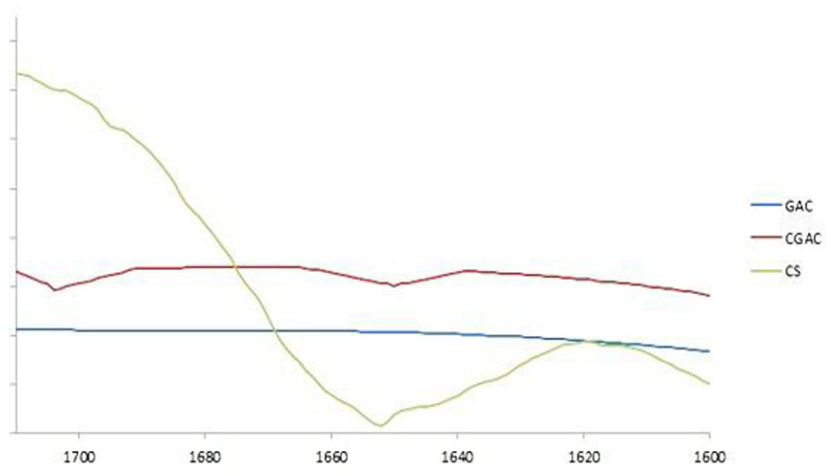

Fig. 2. Fourier transforms infrared spectroscopy spectrums of granular activated carbon (GAC), commercial granular activated carbon (CGAC), and commercial chitosan (CS).

Table 1. BET Surface Area and lodine Number Analysis Results

\begin{tabular}{lcccc}
\hline Sample & $\begin{array}{c}\text { Specific } \\
\text { surface area } \\
\left(\mathrm{m}^{2} / \mathrm{g}\right)\end{array}$ & $\begin{array}{c}\text { Total pore } \\
\text { volume } \\
\left(\mathrm{cm}^{3} / \mathrm{g}\right)\end{array}$ & $\begin{array}{c}\text { Mean } \\
\text { diameter } \\
(\mathrm{mm})\end{array}$ & $\begin{array}{c}\text { Iodine } \\
\text { number } \\
(\mathrm{mg} / \mathrm{g})\end{array}$ \\
\hline GAC & 301.9 & 0.16 & 2.18 & 137.17 \\
CGAC & 531.3 & 0.29 & 2.15 & 120.30 \\
\hline
\end{tabular}

BET: Brunauer-Emmett-Teller, GAC: granular activated carbon, CGAC: commercial granular activated carbon. 
Conclusion, impregnation with Chitosan will have more amino ketone and aldehyde functional group while other functional group is not clearly different.

\subsection{Scanning Electron Microscope Studies}

SEM technique was applied in order to study regarding surface morphology of adsorbent before and after impregnation with chitosan solution. The pictures were shown in Fig. 3. It can be seen that the surface of the GAC and CGAC are not clearly different.

\subsection{Carbon Dioxide Adsorption Result}

Analytical results for purity of outlet $\mathrm{CO}_{2}$ gas were set as the declining point by $50 \%$ of inlet $\mathrm{CO}_{2}$ concentration. GAC and CGAC were degenerated at 49.6 and $80.0 \mathrm{~min}$, respectively (Fig. 4). The maximum adsorption capacity $\left(\mathrm{q}_{\mathrm{m}}\right)$ of $\mathrm{CO}_{2}$ in GAC and CGAC adsorbents were shown in Fig. 5. The maximum adsorption capacity for GAC and CGAC which obtained from the following balance Eq. (1) were 0.174 and $0.249 \mathrm{~mol} / \mathrm{kg}$, respectively. Other available adsorption capacity results were shown in Table 2 .

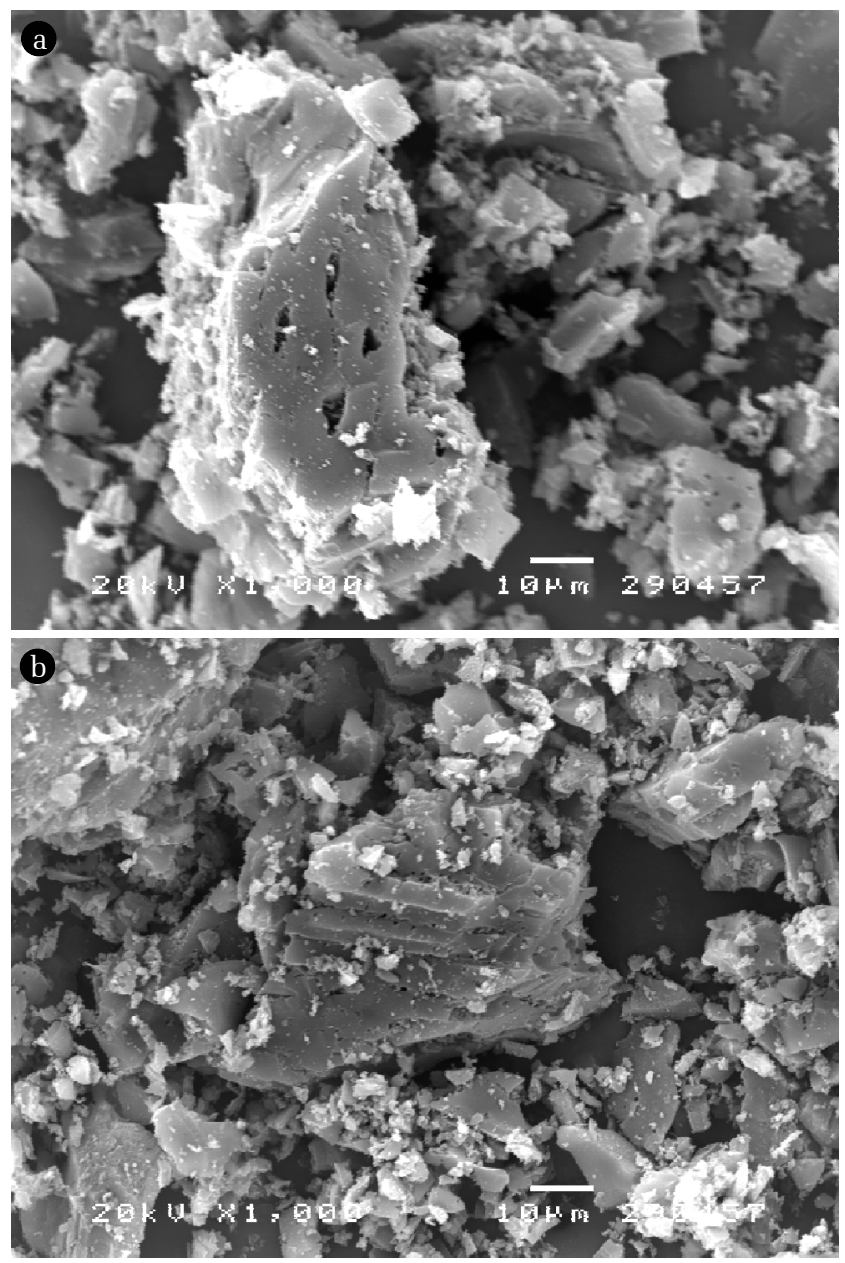

Fig. 3. Scanning electron microscope images of (a) granular activated carbon (GAC) and (b) commercial granular activated carbon (CGAC) at $\times 1,000$.

$$
\begin{gathered}
n_{\text {ads }}=n_{\text {feed }}-n_{e} \\
n_{\text {feed }}=\frac{P_{a d s} \int V_{t} d_{t}}{R T} \\
n_{e}=\frac{P_{e} V_{\text {out }}}{R T}
\end{gathered}
$$

Conclusion, the effect of Chitosan on the increasing of degeneration time (the time which adsorbate starts to release from adsorbent because of full capacity) and maximum adsorption capacity of CGAC because CGAC was with more amino and hydroxyl functional groups than GAC after Chitosan impregnation which well adsorb a weak acid as $\mathrm{CO}_{2}$ than GAC before impregnation with Chitosan [7].

Table 2. Comparison of $\mathrm{CO}_{2}$ Adsorption Capacity of Various Absorbents

\begin{tabular}{lcccc}
\hline \multicolumn{1}{c}{ Sample } & $\begin{array}{c}\text { SSET } \\
\left(\mathrm{m}^{2} / \mathrm{g}\right)\end{array}$ & Condition & $\begin{array}{c}\text { Adsorption } \\
\text { capacity } \\
(\mathrm{mol} / \mathrm{kg})\end{array}$ & Reference \\
\hline SBA-15 & 987 & $303 \mathrm{~K}, 0.1 \mathrm{MPa}$ & 0.047 & {$[9]$} \\
MCM-41 & 1,229 & $348 \mathrm{~K}, 0.1 \mathrm{MPa}$ & 0.0143 & {$[10]$} \\
CMK-3 & 1,098 & $298 \mathrm{~K}, 0.1 \mathrm{MPa}$ & 0.125 & {$[11]$} \\
Si-MCM-41 & 1,486 & $298 \mathrm{~K}, 0.1 \mathrm{MPa}$ & 0.062 & {$[12]$} \\
GAC & 302 & $303 \mathrm{~K}, 0.3 \mathrm{MPa}$ & 0.174 & This work \\
CGAC & 531 & $303 \mathrm{~K}, 0.3 \mathrm{MPa}$ & 0.249 & This work \\
\hline
\end{tabular}
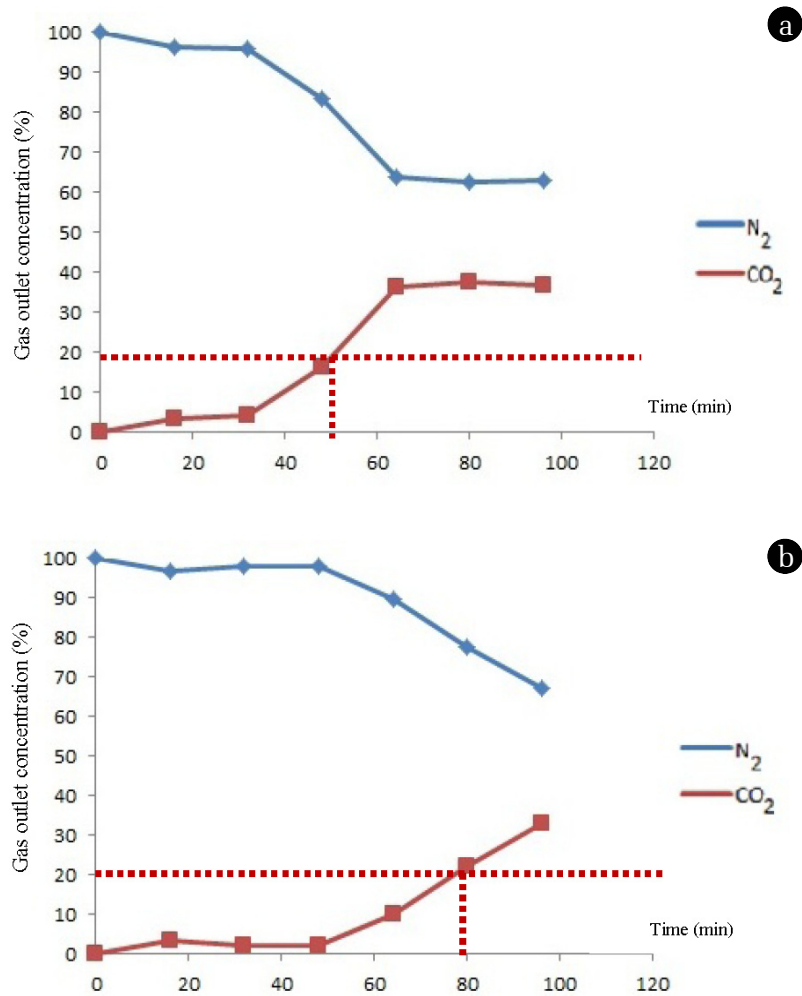

Fig 4. Degeneration time of (a) granular activated carbon and (b) commercial granular activated carbon. 


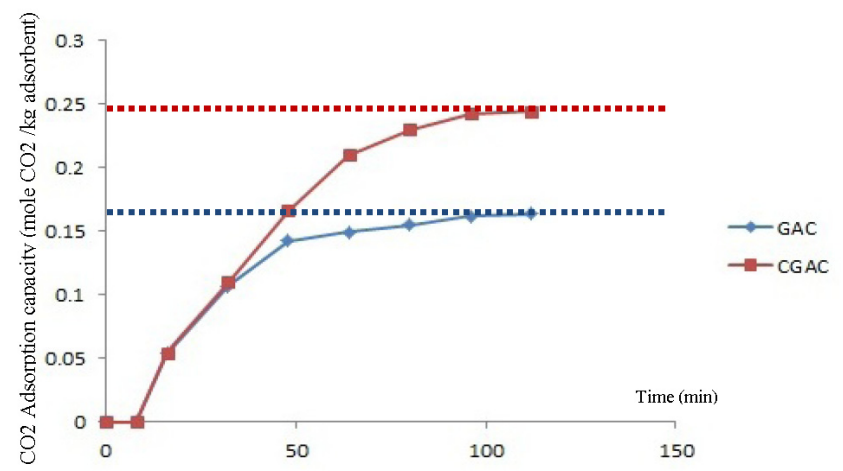

Fig. 5. Adsorption capacity of $\mathrm{CO}_{2}$ on granular activated carbon (GAC) and commercial granular activated carbon (CGAC).

\section{Conclusions}

The impregnation with Chitosan on CGAC has influence to improve the physical characteristics. Including, increasing Specific surface area and total pore volume. Moreover, impregnation with Chitosan of CGAC also increases the degeneration time, maximum adsorption capacity and its adsorption efficiency.

\section{Acknowledgement}

This work was carried out with financial support from the corporation between Thailand Institute of Scientific and Technological Research (TISTR) and Academic Institute on Graduate Program Development. In addition, the authors also acknowledge the financial support from the graduate school, Chulalongkorn University, Thailand.

\section{References}

1. Lee SY, Park SJ. Carbon dioxide adsorption performance of ultramicroporous carbon derived from poly (vinylidene fluo- ride). J. Anal. Appl. Pyrolysis 2014;106:147-151.

2. Plaza MG, González AS, Pevida C, Pis JJ, Rubiera F. Valorisation of spent coffee grounds as $\mathrm{CO}_{2}$ adsorbents for postcombustion capture applications. Appl. Energy 2012;99:272-279.

3. Tantuan P. Effect of pressure and flow rate on carbon dioxide and nitrogen adsorption efficiency. In: 4th National Walailak Research Conference; 2012 June 21; Nakhon Si Thammarat, Thailand. p. 146-147.

4. Lohasarn P. Enhancement of dyes adsorption efficiency on activated carbon from paper pulp sludge by chitosan coat and aeration [dissertation]. Bangkok: Chulalongkorn University; 2008.

5. ASTM International. Standard test method for determination of iodine number of activated carbon. West Conshohocken: ASTM International; 2011. ASTM D4607-94.

6. ASTM International. Test method for specific surface area of carbon or graphite. West Conshohocken: ASTM International; 2011. ASTM C 819-77.

7. Maghsoodloo Sh, Noroozi B, Haghi AK, Sorial GA. Consequence of chitosan treating on the adsorption of humic acid by granular activated carbon. J. Hazard. Mater. 2011;191:380-387.

8. Ngowsuwan C. Adsorption of basic dye and reactive dye by waste sludge [dissertation]. Bangkok: King Mongkut's University of Technology Thonburi; 2005.

9. Huang CC, Shen SC. Adsorption of $\mathrm{CO}_{2}$ on chitosan modified CMK-3 at ambient temperature. J. Taiwan Inst. Chem. Eng. 2013;40:89-94.

10. Ma X, Wang X, Song C. "Molecular basket" sorbents for separation of $\mathrm{CO}(2)$ and $\mathrm{H}(2) \mathrm{S}$ from various gas streams. J. Am. Chem. Soc. 2009;131:5777-5783.

11. Zhou L, Liu X, Li j, Wang N, Wang Z, Zhou Y. Synthesis of ordered mesoporous carbon molecular sieve and its adsorption capacity for $\mathrm{H}_{2}, \mathrm{~N}_{2}, \mathrm{O}_{2}, \mathrm{CH}_{4}$ and $\mathrm{CO}_{2}$. Chem. Phys. Lett. 2005;413:6-9.

12. Xu X, Song C, Andrésen JM, Miller BG, Scaroni AW. Preparation and characterization of novel $\mathrm{CO}_{2}$ molecular basket adsorbents based on polymer-modified mesoporous molecular sieve MCM-41. Microporous Mesoporous Mater. 2003;62:29-45. 